\title{
Spinal anesthesia for Cesarean delivery in a parturient with spondylocostal dysostosis
}

\author{
James A. Dolak, MD, PhD · Shane Tartt, MD
}

Received: 20 May 2008/Revised: 10 November 2008/ Accepted: 17 November 2008/Published online: 27 January 2009

(C) Canadian Anesthesiologists' Society 2009

\section{To the Editor,}

Spondylocostal dysostosis (SCD) is a form of shorttrunked dwarfism resulting from a defect in somitogenesis. ${ }^{1}$ Both general (GA) and neuraxial anesthesia (NA) may present anesthetic challenges in these patients.

A 40-yr-old multiparous woman $\left(\mathrm{G}_{6} \mathrm{P}_{3}\right), 140 \mathrm{~cm} 59 \mathrm{~kg}$, with SCD was examined in anticipation of a planned repeat Cesarean delivery (CD). She had one prior vaginal delivery and two CDs. All previous surgeries were performed under $\mathrm{GA}$. Due to intraoperative awareness with a prior $\mathrm{CD}$, she requested use of NA.

The patient's physical examination revealed a short trunk with disproportionately long extremities and the presence of scoliosis. Her airway examination revealed a restricted neck extension, a $3.5 \mathrm{~cm}$ thyromental distance, and a normal mouth opening with a Mallampati II classification. No evidence of cardiopulmonary dysfunction was noted and laboratory studies were unremarkable. A spinal magnetic resonance imaging showed multiple vertebral abnormalities along with cervical spinal stenosis and a C3-C4 disc herniation (Fig. 1). Termination of the thecal sac occurred at the level of the L5 vertebral body, with the conus medullaris ending near the L2-L3 interspace.

The operating room (OR) was prepared with an assortment of difficult airway tools, in the event that tracheal intubation became necessary due to either failed or total spinal anesthesia. After aspiration prophylaxis with metoclopramide $10 \mathrm{mg}$ po and sodium citrate/citric acid $(30 \mathrm{ml}$

\footnotetext{
J. A. Dolak, MD, PhD ( $\bowtie)$

Emory Crawford Long Hospital, Atlanta, USA

e-mail: jdolak@emory.edu
}

J. A. Dolak, MD, PhD - S. Tartt, MD

Emory University School of Medicine, Atlanta, USA po), the patient was taken to the $\mathrm{OR}$ and placed in the sitting position. Spinal anesthesia was achieved with some difficulty using $0.75 \%$ spinal bupivacaine $6 \mathrm{mg}$, fentanyl $10 \mu \mathrm{g}$, and preservative-free morphine $100 \mu \mathrm{g}$, by means of a $27-\mathrm{G}$ Quinke ${ }^{\mathrm{TM}}$ needle at the L2-L3 interspace. The patient was then placed supine with left lateral uterine displacement, and a bilateral T3 level to pinprick was attained. A male infant was delivered by CD with Apgar scores of 8 and 9 (at one and five minutes, respectively). After approximately two hours of recovery time, the patient was discharged to the postpartum unit in stable condition. The patient consented to publication of this report and the related images.

Spondylocostal dysostosis can be either a recessive or a dominant trait, and is characterized by multiple vertebrocostal anomalies without severe thoracic impairment. ${ }^{1}$ Costal anomalies include broadening, bifurcation, and fusion; whereas the vertebral defects include block-, wedge-, butterfly-, and hemi-vertebrae. ${ }^{2}$ These malformations may lead to progressive scoliosis. Other anomalies associated with SCD include facial dysmorphism, oropharyngeal abnormalities, torticolis, and patent foramen ovale. $^{3}$

Despite the suggestion that, in the face of short-stature, catheter-based techniques are superior to single-shot techniques, ${ }^{4}$ we chose to use the latter. We thought a flexible spinal needle might be easier to manipulate through the patient's disordered vertebral anatomy. It was unclear if an uninterrupted epidural space was present; therefore, the success of an epidural block was uncertain. Finally, since treating a spinal headache with a blood patch would likely be very difficult, continuous spinal anesthesia would be a poor choice.

It is our practice to adjust the dosage of local anesthetic (LA) in a single-shot spinal, based on the height of the 
Fig. 1 Magnetic resonance images show multiple vertebral anomalies throughout the entire spine, including butterfly-, block-, and hemi-vertebra (coronal view). A moderate scoliosis can also be appreciated. Note, also, the total derangement of the posterior spinous processes (saggital view)
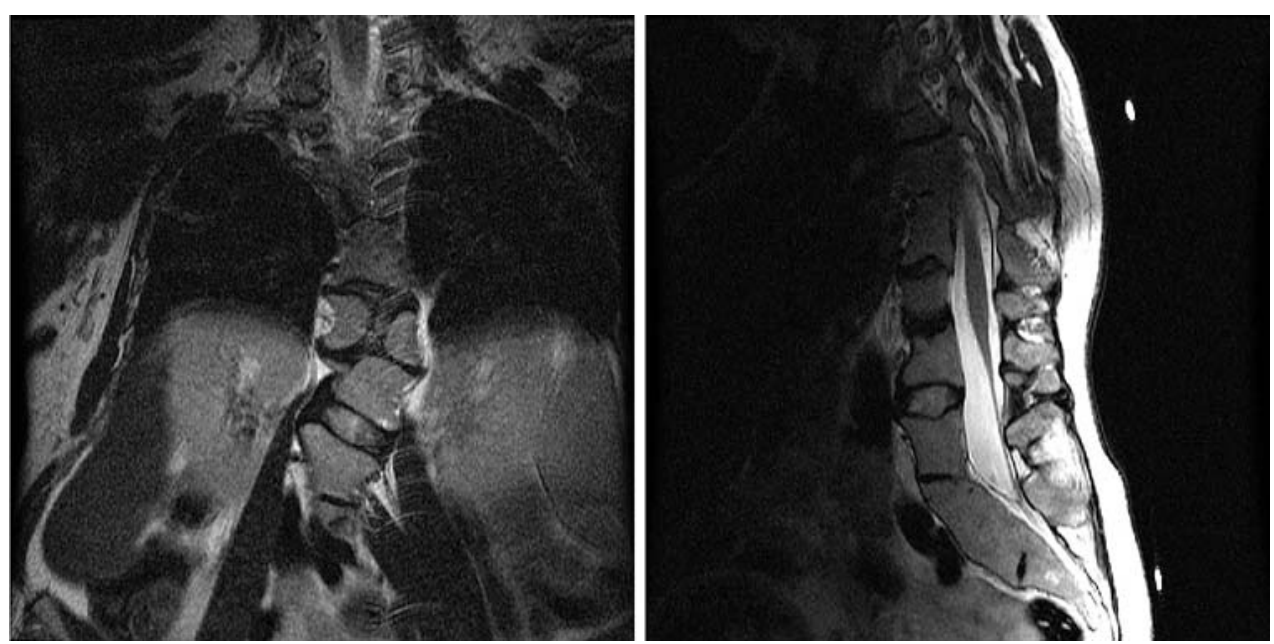

parturient, and it is believed that LA dosing must be adjusted in circumstances of uncommonly short stature. ${ }^{5}$ In such individuals, thoracosacral length, rather than raw height, is a better guide to LA dosing.

The SCD patient presenting for surgery requires an individualized anesthetic plan. General anesthesia may be complicated by airway difficulties resulting from cervical spine abnormalities, as well as from facial and oropharyngeal dysmorphisms. Even moderate thoracic restriction in the SCD patient might complicate mechanical ventilation. On the other hand, vertebral anomalies may make NA mechanically difficult. As both epidural and intrathecal volumes are reduced, a significant decrease in LA dosage will be required. Review of spinal imaging may greatly assist in determining the viability of NA.

\section{References}

1. Shifley ET, Cole SE. The vertebrate segmentation clock and its role in skeletal birth defects. Birth Defects Res C Embryo Today 2007; 81: 121-33.

2. Turnpenny PD, Alman B, Cornier AS, et al. Abnormal vertebral segmentation and the notch signaling pathway in man. Dev Dyn 2007; 236: 1456-74.

3. Cornier AS, Ramirez N, Carlo S, Reiss A. Controversies surrounding Jarcho-Levin syndrome. Curr Opin Pediatr 2003; 15: 614-20.

4. Ratner EF, Cohen SE. Parturients of short stature. In: Gambling DR, Douglas MJ, editors. Obstetric Anesthesia and Uncommon Disorders, 1st ed. Philadelphia: W.B. Saunders Company; 1998: 183-94.

5. Harten JM, Boyne I, Hannah P, Varveris D, Brown A. Effects of a height and weight adjusted dose of local anaesthetic for spinal anaesthesia for elective caesarean section. Anaesthesia 2005; 60: $348-53$.

Funding None.

Conflicts of interest None declared. 